\title{
The Effect of Music on Moroccan Students' Acceptance of Kahoot Gamified Quizzing in the EFL Classroom
}

\author{
Abderrahim Mimouni \\ Ibn Zohr university, Morocco \\ abderrahim.mimouni@edu.uiz.ac.ma \\ Youssef Tamer \\ Ibn Zohr university, Morocco \\ y.tamer@uiz.ac.ma
}

DOI: http://doi.org/10.36892/ijlls.v2i2.303

\begin{tabular}{ll}
$\begin{array}{l}\text { Received: } \\
\text { 01/02/2020 }\end{array}$ & $\begin{array}{c}\text { Abstract } \\
\text { Accepted: }\end{array}$ \\
20/04/2020 & that add game elements to gamify learning content in English as a Foreign \\
& Language $(E F L)$ classroom. Yet, identifying what specific game elements in \\
& these technologies have a significant impact on students' perceptions has not \\
& received much attention. This quasi-experimental study aimed at exploring the \\
\hline Keywords: & effect of Kahoot music on Moroccan students' acceptance of Kahoot gamified \\
Gamification; & quizzing in the EFL classroom. Two intact groups of secondary school students \\
Kahoot; & were recruited for this study. One group played Kahoot Gamified Quizzes \\
Game-based learning & without music, while the other group played the same quizzes with music. The \\
& results of the independent samples t-test showed that the students in both groups \\
& perceived Kahoot gamified quizzing positively and that music had no significant \\
& effect on their perceptions.
\end{tabular}

\section{INTRODUCTION}

One approach that has prevailed in the last decade in education and in many other fields is gamification. The term, "Gamification", has been used to refer to the process of integrating game thinking and game mechanics in a non-gaming context (Deterding, Khaled, Nacke, \& Dixon, 2011; Zichermann \& Cunningham, 2011; Kapp, 2012). Gamification is believed to advance goals outside the context of a game (Brigham, 2015). In educational contexts, game elements (colors, bonuses, feedback, music, countdown timer, leaderboards, and points) are imported into learning activities such as quizzes to increase engagement, motivation, and learning and to solve problems (Zichermann \& Cunningham, 2011; Kapp, 2012, 2016; Morschheuser, Rivera-Pelayo, Mazarakis, \& Zacharias, 2014; Brigham, 2015).

The enormous growth of mobile technologies in the last decade encouraged more enhanced digitization of quizzes and paved the way for more gamification of learning content (Wang, 2015). Particularly, the advent of smartphones and tablets has blessed users with enormous opportunities to easily access wireless networks and HTML wherever they are. Therefore, taking advantage of these new facilities stimulated the designers of educational applications and opened the door for a new conception of the whole quiz-delivery and response experience in the classroom. Unsurprisingly, the outcome was the shift to a new generation of web-based applications(such as Kahoot, Socrative, Quizizz, and Quizlet) that provide more interactive platforms with tempting graphical and audio effects which add game elements and turn quizzes into a game (Wang, 2015; Wang, Zhu, \& Sætre, 2016). Several studies have reported significant effects of these applications on students' perceptions and academic 
performance (Coca \&Slisko, 2013; Elliott, 2015; Hussein \&Picciano, 2015; Wang, 2015; Fotaris, Mastoras, Leinfellner, \&Rosunally, 2016; Wang \& Lieberoth, 2016; Wang et al., 2016; Chaiyo \& Nokham, 2017). Yet, more research is needed to explore the effect of each of the game elements added to the quizzes on student's perception (Heong, Filippou, and Cheong, 2014; Wang and Lieberoth, 2016) and especially in the EFL classroom.

In Morocco, the need to use technology in the classroom in order to improve the quality of learning and instruction has always been a primary concern since the issue of the National Charter of Education and Training of 1999. A number of projects have come into existence to incorporate and investigate the effectiveness of using technological tools into the classroom (Hamdy, 2007; Naciri, 2015; Ait Hammou \& Elfatihi, 2019). However, the use of digital games and technologies that gamify learning content has not yet been sufficiently investigated within the Moroccan classroom. So far, much of the work on the use of digital games or gamification within the Moroccan context has been focused on theory-based propositions with no recorded data form the classroom (Lamrani \& Abdelwahed, 2016; Zeroual, El Kah, \& Lakhouaja, 2017). Therefore, more empirical research is needed to investigate the effectiveness of these technologies within the Moroccan classroom and particularly from the perspective of the primary stakeholders, students.

This paper reports the findings of a quasi-experimental study that aimed at exploring the effect of music of the gamified response system, Kahoot, on Moroccan students' acceptance of Kahoot gamified quizzing in two EFL classrooms. The second section of the paper presents the review of the literature, and the third explains the research methodology. The fourth section reports the research findings while the fifth discusses and explains the conclusions drawn from the findings.

\section{LITERATURE REVIEW}

Research has shown that the applications that gamify learning content have great potentials to influence behavior and increase learning in educational settings. Initially, the literature has praised these technologies for their potential to increase students' motivation (Wang, 2015; Wang \& Lieberoth, 2016; Wang et al., 2016). Specifically, the game elements that are cultivated through the graphics and audios of these technologies make the quizzes fun and intrinsically motivating (Wang, 2015; Wang \& Lieberoth, 2016; Wang et al., 2016). Also, these technologies allow the participants to form teams to respond to the questions and to discuss their answers. Therefore, they have been said to encourage collaboration and interaction among students (Kiryakova, Angelova, \& Yordanova, 2014; Brigham, 2015; Wang, 2015; Wang et al., 2016). Further, these technologies have the potential to provide instant feedback about students' learning (Coca \& Slisko, 2013; Elliott, 2015; Hussein, 2015; Wang, 2015; Fotaris, Mastoras, Leinfellner, \& Rosunally, 2016; Chaiyo \& Nokham, 2017). According to Brigham (2015), instant feedback coupled with collaborative learning can satisfy the requirements of learners, particularly, millennials.

The potentials of digital gamified platforms and applications to enhance learning in the EFL classroom have also been explored. Research has indicated that using applications that inject game elements (such as music, colors, bonuses, feedback, countdown timer, leaderboards, and points) into learning content help students learn and improve their language skills. To begin with, a number of recent studies suggested that these technologies enhance intrinsic motivation and help students learn grammar more effectively than other traditional language teaching approaches (Zarzycka-Piskorz, 2016; Karaaslan, Kilic, Guven-Yalcin, and Gullu, 2018). Similarly, it has been demonstrated that using these tools contribute significantly to students' learning of English vocabulary (Dizon, 2016). Additionally, using gamified technologies can increase students' writing skills (Stanley, 2014). Furthermore, Karaaslan et al. (2018) reported that these tools help students practice higher-order skills in a relaxed and 
interactive atmosphere with peers' interaction, instructor's supervision and the immediate feedback of the digital game platforms.

In the light of the literature reported here, it is conceivable that the applications that inject game elements into learning content seem to play a significant role in motivating students and enhancing students' language learning. Yet, it is not clear what specific game elements in these technologies contribute significantly to students' learning. This question has not received much attention in the literature (Heong, Filippou, and Cheong, 2014; Wang and Lieberoth, 2016), and especially within the context of language learning. Very few studies have tried to unpack the question, but not within the context of language learning. For instance, Cheong, Filippou, and Cheong, (2014) reported in their study some information about what game elements can assist students with their learning in an Information Technology undergraduate course. In detail, their study investigated the perceptions of 51 undergraduates toward game elements including points, leader boards, player profiles, progress bars, and achievement badges. The findings of the study revealed that the majority of the participants expressed positive perceptions toward these game elements. Most importantly, the participants believed that points and leader boards could be used to promote competition, while points and player profiles could provide feedback on the users' performance. In addition to this, the findings showed that progress bars motivate the users to complete tasks while achievement badges motivate them to master the task. Wang and Lieberoth (2016) also attempted to approach the question in an Information Technology undergraduate course through investigating the effect of audio and points of Kahoot gamified quizzing on students' perceived concentration, engagement, enjoyment, learning, motivation and classroom dynamics. The findings of the study showed that the use of audio and points had a significant effect on students' concentration, enjoyment, and motivation, whereas there was no significant difference in perceived learning (how the students perceived whether they learned something from playing the quiz). More interestingly, the study revealed that there was some tendency that students learned more when there is no points and no audio. Regarding classroom dynamics, the researchers observed that the use of audio had the largest impact on students' interaction, response and spirit.

Overall, most of the studies, especially those conducted in the EFL classroom, did not focus on studying the effect of single game elements on students' learning, but rather investigated the effectiveness of the applications that gamify learning content as a whole. This holistic approach is very important as it has yielded interesting data on gamification and the implementation of these applications in particular. Nevertheless, knowing what specific game elements significantly impact on students' learning is essential as it can provide more information to inspire, guide, or even correct the design and development of these applications. The studies done in other disciplines such as Information Technology undeniably offer compelling data in this regard. However, approaching the question from the perspective of language learners will contribute to a better insight into how gamification can serve the objectives of language learning. The present study is an attempt to do this by measuring the effect of Kahoot music on secondary school students' acceptance of Kahoot gamified quizzing in the EFL classroom.

\section{METHODOLOGY}

\section{Design}

To measure the effect of music of the gamified response system Kahoot on students' acceptance of Kahoot gamified quizzing in EFL classroom, a quasi-experimental nonequivalent control group design (Campell \& Stanley, 1963; Gall, Gall, \& Borg, 2003; Creswell, 2014) was used in this study. Two intact groups were randomly assigned to either group-1, the group of students who played Kahoot gamified quizzes without music (Kahoot 
music turned on) and group-2, the group of students who played the same gamified quizzes with music (Kahoot music turned off). The two groups were taught two English Grammar lessons (Gerund/Infinitive and Modals) by the same instructor. Also, they both played a gamified quiz by the end of each lesson. Kahoot, a free gamified students response system that gamifies the quiz delivery and response experience (Wang et al., 2016), was used in this study to create and deliver the quizzes. The way the gamified quizzes were implemented, without music (for group 1) and with music (for group2) served as the independent variable for this study. Students' perceptions of gamified quizzing usefulness and ease of use served as the dependent variables. The design of the study is depicted below (see Figure 1).

Figure 1. Study design

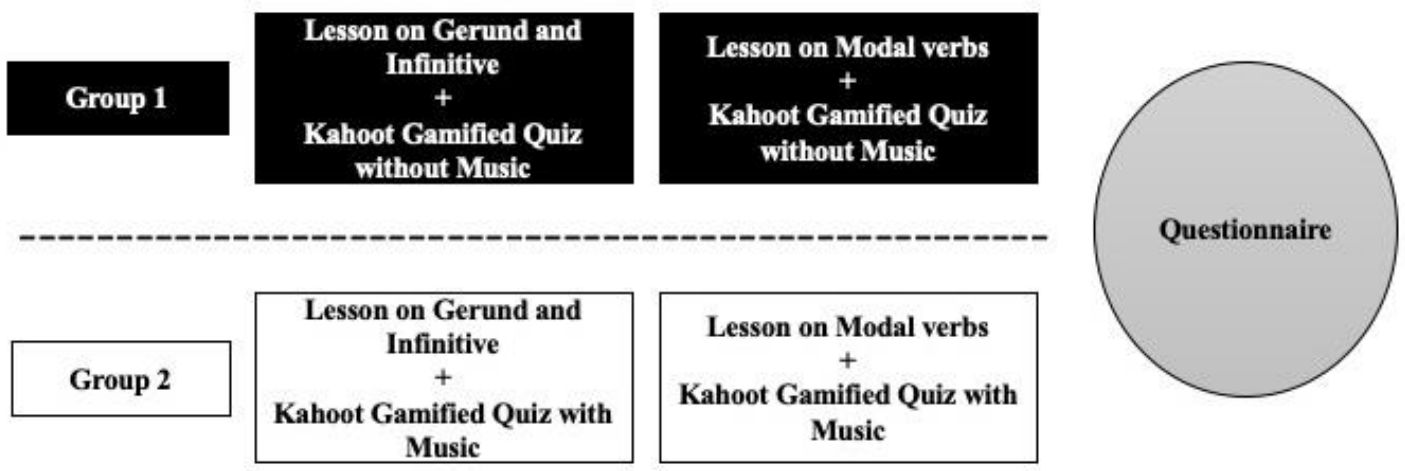

\section{Questions and hypotheses}

The main objective of this study is to measure the effect of music of the gamified response system Kahoot on students' acceptance of Kahoot gamified quizzing in the EFL classroom. Therefore, the main research question (RQ) is:

RQ. Is there a significant difference in perceptions of the students who play the gamified quizzes with music and those who play the same gamified quizzes without music?

To answer this question, the following hypotheses were developed for this study:

$\mathrm{H}_{1}$. The students who play the gamified quizzes with music perceive gamified quizzing significantly better than students who play the same gamified quizzes without music.

$\mathrm{H}_{0}$. There is no significant difference in perceptions of the students who play the gamified quizzes with music and those who play the same gamified quizzes without music.

\section{The participants}

The participants for the study were drawn from a convenience sample of $2^{\text {nd }}$ year Baccalaureate students at Mohamed Ben Hassan EL-Khayat secondary school in Inezgane, Morocco, during the fall semester of 2019-2020. The total number of participants sampled was 45 with 23 in group- 1 and 22 in group- 2 . Of the 45 participants, 25 were females and 20 were males. The participants' median age was 17.

\section{Instrument}

To measure students' perceptions of the use of gamified quizzing, a questionnaire based on the measurement scales of perceived usefulness and perceived ease of use (Davis, 1989) was used in the present study. The questionnaire included two constructs. The first construct was built on six items intended to examine perceived usefulness of gamified quizzing; the degree the participants believe gamified quizzing enables them to improve their performance. The second construct included six items too and aimed to probe perceived ease of use, the degree the participants believe it is free of effort. All the items in the questionnaire were measured using a 5-point Likert scale $(1=$ Strongly disagree, $2=$ disagree, $3=$ neutral, $4=$ 
agree, and $5=$ Strongly agree). The questionnaire was developed originally by Davis (1989) to measure users' perceptions of technological apps. The scales of the questionnaire were constructed on solid theoretical grounds and were attested validity under different conditions and in various environments ( Hwang, Hung, \& Chen, 2013; Dizon, 2016; Ab. Rahman, Ahmad, \& Hashim, 2018). Cronbach alpha coefficient was measured to examine internal reliability of the instrument, and both scales obtained scores above .9 granting the questionnaire strong reliability. The questionnaire is a free open access measurement that can be adapted to suit different research objectives. In the present study, the words "gamified quizzes" were used to replace the technological system "Chart Master" used in the original Questionnaire of Davis (1989). Also, the workplace-related words were replaced by other words related to learning and classroom language for more clarity of the items. Both groups of the independent variable, those who were exposed to the gamified quizzes without music and those who experienced the same gamified quizzes with music, completed the questionnaire toward the end of the study.

\section{Research Procedure}

Prior to the experiment, the participants in both groups (1 and 2) took part in a workshop given by the instructor on how to use the gamified response system "Kahoot" and how to play the gamified quizzes. The participants had more opportunities to ask and get answers on how to play the gamified quizzes. Additionally, the workshop ended with a demonstration during which students had to respond to a five-item vocabulary gamified quiz to get more acquainted with the gamified quizzes.

During the experiment, both group 1 and group 2 took two English grammar classes by the same instructor. The first class was about "Gerund and Infinitive", and the second class was about "Modal verbs". Each class lasted one hour, 40 minutes for the lesson and 20 minutes for the gamified quiz. The instructor used the course book and coursebook-based Power-points presentations to teach "Gerund and Infinitive" and "Modal verbs". At the end of every class, the students in both groups played in groups of threes a ten-item gamified quiz on the class content. Playing Kahoot gamified quizzes individually was impossible due to that fact that the room was not equipped with WIFI connection and the fact that some students did not have their personal devices.The major difference between group1 and group 2 was the way how Kahoot gamified quizzes were implemented, without music (for group 1) and with music (for group 2 ). At the end of the experiment, both groups completed the questionnaire for their perceptions on the usefulness and ease of use of Kahoot gamified quizzing. The students completed the questionnaire in the classroom; therefore, they had opportunities to ask for clarifications about the items they did not understand.

\section{Data Analysis Procedure}

To test statistically the research hypotheses of the present study, both descriptive statistics and the parametric independent samples t-test were used to analyze the collected data through IBM SPSS 25. The descriptive statistics were used to describe the participants' mean scores and to check for t-test assumptions. The inspection of histograms, Q-Q plots, box plot, and Shapiro-Wilk test confirmed that all the collected data on both perceived usefulness and ease of use passed the assumptions of normal distribution. Similarly, Levene's test confirmed that there was no violation of equal variance assumptions. Subsequently, the independent samples t-test was carried out to check if the differences between group1 and group 2 in terms of perceived usefulness and perceived ease of use are statistically significant $(p<.05)$.

\section{RESULTS}

The research hypothesis suggests that students who play the gamified quizzes with music perceive gamified quizzing significantly better than those who play the same gamified quizzes 
without music. The statistical analysis of the collected data about both perceived usefulness and perceived ease of use was processed using IBM SPSS 25 software. The analysis and results are described and summarized as follows.

Error! Reference-source not found.Figure 2 presents the results of students' mean scores on the level of perceived usefulness as measured by the perceived usefulness scale for the two groups of the independent variable;group1 (no music group) and group 2 (music group). According to Figure 2, both Groups 1 and 2 perceived gamified quizzing positively; however, mean score $(M=4.42, S D=.29)$ of group 1 is slightly higher than that of group $2(M=$ $4.39, S D=.34)$.

\section{Figure 2. Mean scores of perceived usefulness by groups}

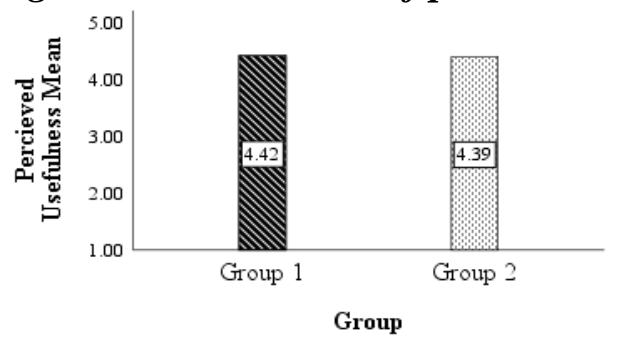

Similarly, Figure 3 compares the mean of students' scores on the level of perceived ease of use as measured by the perceived ease of use scale for the two groups of the independent variable; group 1 (no music group) and group 2 (music group). Based on Figure 3, although gamified quizzing was perceived positively as easy to use by both Groups 1 and 2, group 1 scored $(M=4.50, S D=.28)$ relatively higher than group $2(M=4.33, S D=.31)$ in terms of perceived ease of use.

Figure 3. Mean score of perceived ease of use by group

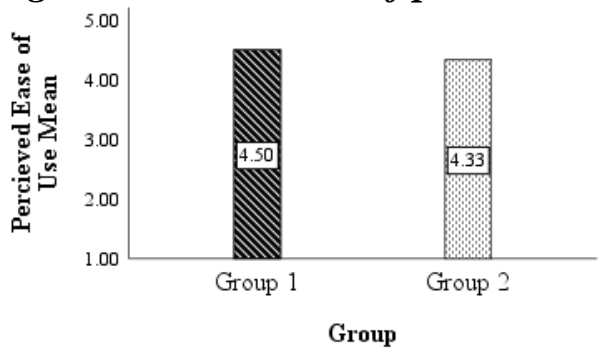

To check if the differences between group 1 and group 2 in terms of perceived usefulness and perceived ease of use are statistically significant $(\mathrm{p}<.05)$, the parametric independent $\mathrm{t}-$ test was used to analyze the data through IBM SPSS 25 software. Before conducting the independent samples t-test analysis, the required methodological and statistical measures were taken to ensure the data collected from the sample meet t-test assumptions. First, to verify the normality of distribution assumption for the data collected on students' perceived usefulness of gamified quizzing, the visual inspection of histograms, Q-Q plots, box plot, and ShapiroWilk test all were accurately checked. The visual investigation of histograms Q-Q plots and box plots showed an approximately normal distributions of data for both groups of the independent variable (Groups 1 and 2) with skewness of .114 $(S E=.491)$ and kurtosis of $.461(S E=.953)$ for group 1 and skewness of $.275(S E=.501)$ and kurtosis of $-.962(S E=.972)$ for group 2. These results were attested by the Shapiro-Wilk test (Shapiro \& Wilk, 1965) that showed a level of significance higher than $\alpha=.05$ for both the group $1(p=.602)$ and group 2 $(p=.286)$. Accordingly, the data on students' perceived usefulness of gamified quizzing passed the assumption of normal distribution. Likewise, the histograms, Q-Q plots and box plots for the data collected on students' perceived ease of use of gamified quizzing indicated an 
approximate normal distribution of the scores for both groups of the independent variable (group 1 and group 2) with skewness of .260 (SE = .491) and kurtosis of .778 (SE = .953) for group 1 and skewness of $-.253(\mathrm{SE}=.501)$ and kurtosis of $-.278(\mathrm{SE}=.972)$ for group 2. Furthermore, the Shapiro-Wilk test (Shapiro \& Wilk, 1965) confirmed the results level of significance greater than $\alpha=.05$ for both group $1(p=.259)$ and group $2(p=.622)$. Accordingly, the data collected on students' perceived ease of use of gamified quizzing passed the assumption of normal distribution. Additionally, the homogeneity of variance assumption was tested via Levene's test. The results showed that there was no evidence of a violation of the equal variance assumptions (see Table 1). The $F$ value for the data collected on students' perceived usefulness of gamified quizzing is (.882), with a significance level $(p=.353)$, that is greater than $\alpha=.05$, and the $F$ value for the data collected on students' perceived ease of use of gamified quizzing is (.040), with a significance level $(p=.842)$, that is greater than $\alpha=.05$.

Accordingly, an independent-samples t-test was conducted to compare the levels of perceived usefulness and perceived ease of use of group 1 (no music group) to the levels of perceived usefulness and perceived ease of use of group 2 (music group). Based on Table 1, there was no significant difference in the scores of perceived usefulness toward gamified quizzing for group 1 and group $2 \mathrm{t}(41)=.234 \mathrm{p}=.816$. Likewise, there was no significant difference in the scores of perceived ease of use toward gamified quizzing for group 1 and group 2t $(41)=1.641, \mathrm{p}=.073$.

Table 1.t-Test result of students' perceptions toward gamified quizzing of the two groups

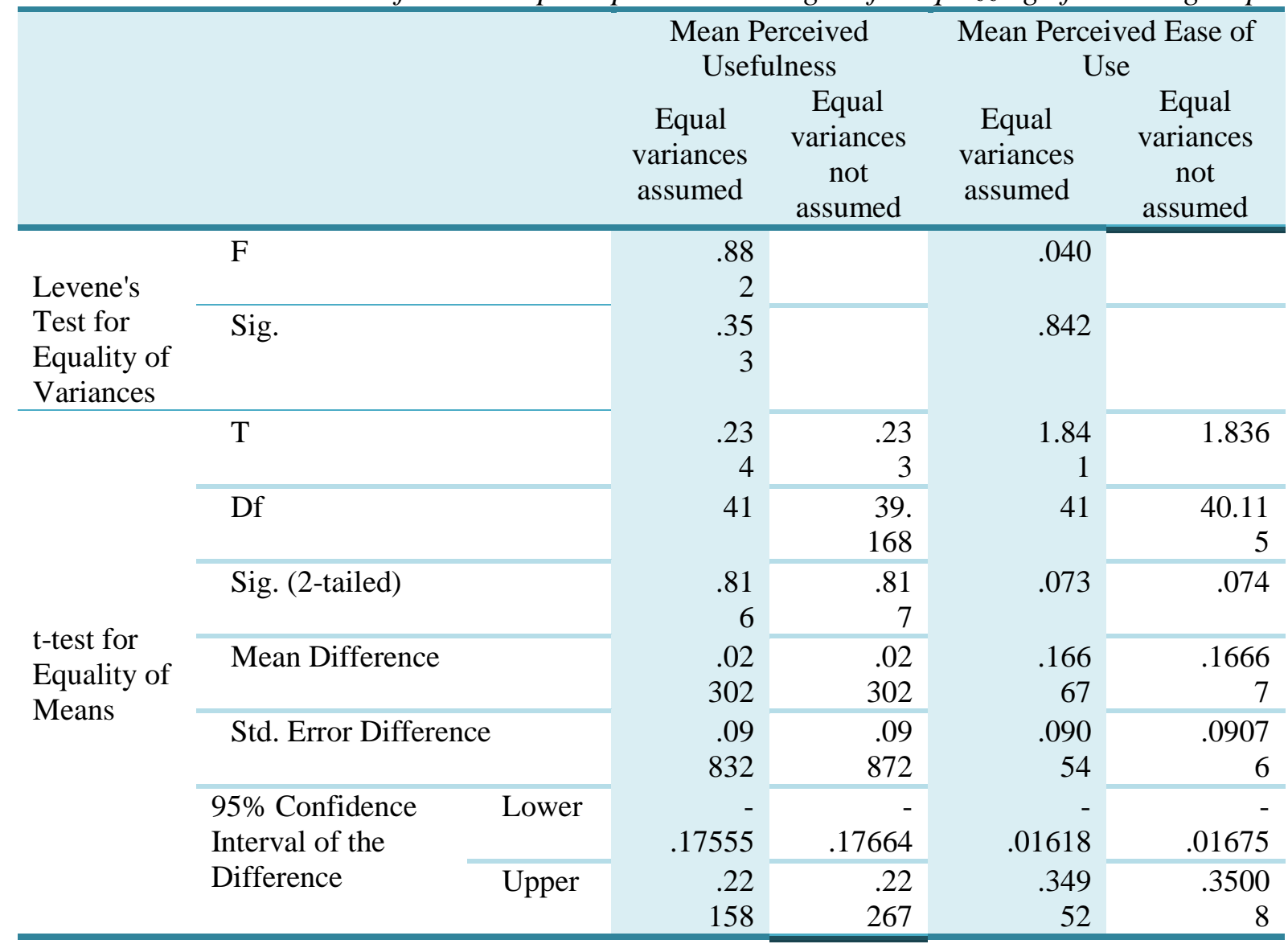

The research hypothesis suggests that students who play the gamified quizzes with music perceive gamified quizzing significantly better than students who play the same gamified quizzes without music. The null hypothesis $\left(H_{0}\right)$ states that there is no significant difference in perceptions of the students who play the gamified quizzes with music and those who play the 
same gamified quizzes without music. The results of the independent samples t-test failed to reject the null hypothesis as there was no significant difference in the scores of perceived usefulness $(\mathrm{t}(96)=-1.466, \mathrm{p}=.146)$ and in the scores of perceived ease of use $(\mathrm{t}(96)=-.311$, $\mathrm{p}=.756$ ) toward gamified quizzing for the two groups of the independent variable; group 1 (no music group) and group 2 (music group).

\section{DISCUSSION}

The current study attempted to examine the effect of music on Moroccan students' acceptance of Kahoot gamified quizzing in the EFL classroom. Mainly, the study compared the perceptions of the students who played the gamified quizzes without music (group 1) to those of the students who played the same gamified quizzes with music (group 2). The findings of the study showed that both group-1 and group-2 perceived gamified quizzing positively in terms of usefulness and ease of use and that there was no significant difference in their perceptions. Music accordingly appears to have no significant effect on students' acceptance of Kahoot gamified quizzing. On the whole, the positive perceptions of students toward gamified quizzing in the present study confirm the findings of a number of studies that reported positive perceptions of students toward gamification and gamified applications(Cheong, Filippou, \& Cheong, 2014; Stanley, 2014; Dizon, 2016; Zarzycka-Piskorz, 2016; Rajšp, et al., 2017; Yildirim, 2017; Ab. Rahman, et al., 2018; Bicen \& Kocakoyun, 2018; Karaaslan et al., 2018; Ortega-Arranz et al., 2019). Regarding the effect of music on students' perceptions toward Kahoot gamified quizzing, the results of the present study, especially those on perceived usefulness, partly agree with the findings of Wang and Lieberoth (2016) who concluded in their study that music and points had no significant effect on students' perceived learning.

Based on the findings of the present study, it seems pretty conceivable that students' perceptions toward Kahoot gamified quizzing are probably influenced significantly by some factors other than music. According to Ab. Rahman et al. (2018), students tend to build their positive perceptions toward gamification based on the ease of the gamified applications and platforms rather than on the benefits they can get from the gamification. Therefore, the results of the current study on students' perceived ease of use might explain to some extent why students hold holistically positive perceptions toward Kahoot gamified quizzing regardless of the use of music. Probably, the students get overwhelmed by Kahoot technology which enables them to use their own mobile devices (smartphones, tablets, or laptops) and grants them a hightech response experience. Further, the effect of music might be overshadowed by the effect of other game elements such as instant feedback. The latter, according to previous literature, can have a great impact on students' learning ( Coca \& Slisko, 2013; Brigham, 2015; Elliott, 2015; Hussein, 2015; Wang, 2015; Fotaris et al., 2016; Chaiyo \& Nokham, 2017;). Correspondingly, it has the potential along with other game elements to significantly influence students' perceptions. Moreover, other factors such as class size and educational level might greatly impact on students' perceptions of gamification (Buckley et al., 2017).

Given the issue that the present study has addressed, these findings are so important as they yield a number of theoretical and practical implications. First, they add to the current literature on gamification, in general, and contribute particularly to a better insight into the effect of specific game elements from the perspective of EFL learners. In addition to this, the present study provides evidence to encourage instructors, especially at the level of secondary school, to use applications and technologies that gamify learning to improve their students' learning. Lastly, this study offers the designers and developers of such technologies significant data on the use of these tools within language classroom.

\section{CONCLUSION}


The current study has systematically provided significant data on the effect of Kahoot music and the use of Kahoot gamified quizzing from the perspective of EFL learners. Nonetheless, these findings should be taken with caution due to some limitations in the study. As explained above, the participants in the study were drawn from a convenience sample of $2^{\text {nd }}$ year Baccalaureate students at Mohamed Ben Hassan EL-Khayat secondary school in Inezgane, Morocco. While this kind of sampling facilitated conducing the study, it might limit generalization to the entire population of EFL secondary school students taught by other instructors. Also, it is worth mentioning that the study did not consider the cultural and socioeconomic variations among the participants. Considering such variations might yield different results.

The issue of what game elements in the technologies that gamify learning content significantly impact on students' learning has not been sufficiently investigated yet, and especially in the EFL classroom. The present study contributes to filling this gap in the literature. Therefore, the limitations listed here do not undermine its significance in adding value to empirical research on gamification, but rather call for more research on this issue. To enrich the literature, future research is needed to recruit larger samples and to cover other courses and other schools over different time frames and under various research designs

\section{REFERENCES}

Ab. Rahman, R., Ahmad, S., \& Hashim, U. R. (2018). The effectiveness of gamification technique for higher education students engagement in polytechnic Muadzam Shah Pahang, Malaysia. International Journal of Educational Technology in Higher Education, 15(1). https://doi.org/10.1186/s41239-018-0123-0

Ait Hammou, Y., \& Elfatihi, M. (2019). Moroccan Teachers' Level of ICT Integration in Secondary EFL Classrooms. International Journal of Language and Literary Studies, 1(3), 1-19. https://doi.org/10.2139/ssrn.3512911

Bicen, H., \& Kocakoyun, S. (2018). Perceptions of students for gamification approach: Kahoot as a case study. International Journal of Emerging Technologies in Learning, 13(2), 7293. https://doi.org/10.3991/ijet.v13i02.7467

Brigham, T. J. (2015). An Introduction to gamification: Adding game elements for engagement. Medical Reference Services Quarterly, 34(4), 471-480. https://doi.org/10.1080/02763869.2015.1082385

Campell, D. T., \& Stanley, J. C. (1963). Experimental and quasi-experimental designs for research on teaching. Chicago: Rand McNally \& Company.

Chaiyo, Y., \& Nokham, R. (2017). The effect of Kahoot, Quizizz and Google Forms on the student's perception in the classrooms response system. 2nd Joint International Conference on Digital Arts, Media and Technology 2017: Digital Economy for Sustainable Growth, ICDAMT 2017, 178-182. https://doi.org/10.1109/ICDAMT.2017.7904957

Cheong, C., Filippou, J., \& Cheong, F. (2014). Towards the gamification of learning: Investigating student perceptions of game elements. Journal of Information Systems Education, 25(3), 233-244.

Coca, D. M., \& Slisko, J. (2013). Software Socrative and smartphones as tools for implementation of basic processes of active Physics learning in classroom: An initial feasibility study with prospective teachers. European Journal of Physics Education, 4(2), 17-24.

Creswell, J. W. (2014). Research design: Qualitative, quantitative, and mixed methods approaches. In Sage (4th ed.). USA: Sage. 
Davis, F. D. (1989). Perceived usefulness, perceived ease of use, and user acceptance of information technology. MIS Quarterly, 13(3), 319-340. https://doi.org/10.1016/S03050483(98)00028-0

Deterding, S., Khaled, R., Nacke, L., \& Dixon, D. (2011). Gamification: toward a definition. CHI 2011 Gamification Workshop Proceedings, 12-15. https://doi.org/978-1-4503-0268-5/11/0

Dizon, G. (2016). Quizlet in the Efl classroom: Enhancing academic vocabulary acquisition of Japanese university students. Teaching English with Technology, 16(2), 40-56. Retrieved from http://www.tewtjournal.org

Elliott, I. (2015). Quizzes and gamification for formative assessment and collaborative learning. (October). Retrieved from https://www.academia.edu/16732102/Quizzes_and_gamification_for_formative_assessm ent_and_collaborative_learning

Fotaris, P., Mastoras, T., Leinfellner, R., \& Rosunally, Y. (2016). Climbing up the leaderboard: An empirical study of applying gamification techniques to a computer programming class. Electronic Journal of E-Learning, 14(2), 94-110. https://doi.org/10.1007/s11528-0160070-3

Gall, M. D., Gall, J. P., \& Borg, W. B. (2003). Educational research: An introduction (7th ed.). Allyn \& Bacon.

Hamdy, A. (2007). ICT in education in Morocco. Retrieved from http://documents.worldbank.org/curated/en/197301468277521349/text/463750BRI0Box3 1 co010ICTed0Survey111.txt

Hussein, B. A. (2015). A blended learning approach to teaching project management: A model for active participation and involvement: Insights from Norway. Educ. Sci, 5, 104-125. https://doi.org/10.3390/educsci5020104

Hwang, G. J., Hung, C. M., \& Chen, N. S. (2013). Improving learning achievements, motivations and problem-solving skills through a peer assessment-based game development approach. Educational Technology Research and Development, 62(2), 129-145. https://doi.org/10.1007/s11423-013-9320-7

Kapp, K. M. (2012). The Gamification of learning and instruction. San Francisco, 480. https://doi.org/10.4018/jgcms.2012100106

Kapp, K. M. (2016). Choose your level: Using games and gamification to create personalized instruction. Handbook on Personalized Learning for States, Districts, and Schools, (In M. Murphy, S. Redding, J. Twyman), 131-143. Retrieved from http://www.centeril.org/2016handbook/resources/Cover_Kapp_web.pdf

Karaaslan, H., Kilic, N., Guven-Yalcin, G., \& Gullu, A. (2018). Students' reflections on vocabulary learning through synchronous and asynchronous games and activities. Turkish Online Journal of Distance Education, 19(3), 53-70. https://doi.org/10.17718/tojde.444640

Kiryakova, G., Angelova, N., \& Yordanova, L. (2014). Gamifcation in education. Proceedings of 9th International Balkan Education and Science Conference., 1-5. https://doi.org/10.4018/978-1-5225-5198-0

Lamrani, R., \& Abdelwahed, E. H. (2016). Learning through play in pervasive context: A survey. Proceedings of IEEE/ACS International Conference on Computer Systems and Applications, AICCSA, 2016-July. https://doi.org/10.1109/AICCSA.2015.7507119 
Morschheuser, B. S., Rivera-Pelayo, V., Mazarakis, A., \& Zacharias, V. (2014). Interaction and reflection with quantified self and gamification: An experimental study. Journal of Literacy and Technology, 15(2), 136-156.

Naciri, H. (2015). Using ICT to improve higher education in Morocco. Conference Proceedings. ICT for Language Learning, 467.

Ortega-Arranz, A., Er, E., Martínez-Monés, A., Bote-Lorenzo, M. L., Asensio-Pérez, J. I., \& Muñoz-Cristóbal, J. A. (2019). Understanding student behavior and perceptions toward earning badges in a gamified MOOC. Universal Access in the Information Society, 18(3), 533-549. https://doi.org/10.1007/s10209-019-00677-8

Rajšp, A., Beranič, T., Heričko, M., \& Horng-Jyh, P. W. (2017). Students' perception of gamification in higher education courses. Central European Conference on Information and Intelligent Systems, 69-75.

Shapiro, S. S., \& Wilk, M. B. (1965). An analysis of variance test for normality ( complete samples ). Biometrika, 52(3/4), 591-611.

Stanley, G. (2014). Using the IWB to support gamification in order to enhance writing fluency in the second language classroom. In Teaching languages with technology: communicative approaches to interactive whiteboard use. A resource book for teacher development (pp. 152-187).

Wang, A. I. (2015). The wear out effect of a game-based student response system. Computers and Education, 82, 217-227. https://doi.org/10.1016/j.compedu.2014.11.004

Wang, A. I., \& Lieberoth, A. (2016). The effect of points and audio on concentration, engagement, enjoyment, learning, motivation, and classroom dynamics using kahoot! Proceedings of the European Conference on Games-Based Learning, 2016-Janua(October), 738-746.

Wang, A. I., Zhu, M., \& Sætre, R. (2016). The effect of digitizing and gamifying quizzing in classrooms. Proceedings of the European Conference on Games-Based Learning, 2016Janua(October), 729-737. https://brage.bibsys.no/xmlui/handle/11250/2426374

Retrieved from

Yildirim, I. (2017). Students' perceptions about gamification of education: A Q-method analysis. Egitim ve Bilim, 42(191), 235-246. https://doi.org/10.15390/EB.2017.6970

Zeroual, I., El Kah, A., \& Lakhouaja, A. (2017). Gamification for Arabic natural language processing: Ideas into practice. Transactions on Machine Learning and Artificial Intelligence, 5(4). https://doi.org/10.14738/tmlai.54.3323

Zichermann, G., \& Cunningham, C. (2011). Gamification by design implementing game mechanics in ebw and mobile apps (1st ed.). USA: O'Reilly Media, Inc.

\section{AUTHORS' BIOS}

Abderrahim MIMOUNI is an EFL instructor. Currently, he is a PhD candidate at Ibn Zohr University, Morocco. His research is focused on the use of gamification for language learning and for enhancing thinking skills.

Dr. Youssef TAMER is a Professor of Applied Linguistics at Ibn Zohr University, Morocco. His research is focused on Teaching and Learning of Languages, Sociolinguistics, Language Planning and Policy, and Educational Technology 